\title{
Leadership \& Professional Development: Breaking the Silence as a Bystander
}

\author{
Melanie F Molina, MD",2*, Sherri-Ann M Burnett-Bowie, MD, MPH ${ }^{3}$
}

'Department of Emergency Medicine, Brigham and Women's Hospital, Boston, Massachusetts; ${ }^{2}$ Department of Emergency Medicine, Massachusetts General Hospital, Boston, Massachusetts; ${ }^{3}$ Department of Medicine, Massachusetts General Hospital, Boston, Massachusetts.

"In the end, we will remember not the words of our enemies, but the silence of our friends."

—Martin Luther King, Jr.

ode Blue, Emergency Department Code Team to PACU." A female senior resident dons her personal protective equipment and assembles her team. An enthusiastic male junior resident asks if he can accompany her, and off they go. They encounter a frantic scene in the post-anesthesia care unit (PACU). Before the senior resident can lead the rapid response, a PACU nurse addresses the junior resident: "You are leading the code, correct? What medications would you like?"

"Microaggressions" are subtle, commonplace exchanges that-whether intentional or unintentional-communicate disparaging messages to members of marginalized groups. ${ }^{1}$ These groups often include women, members of racial/ethnic groups that are underrepresented in medicine, and lesbian, gay, bisexual, transgender, and queer/questioning (LGBTQ) individuals. Although an individual may not intend to cause harm, their words may still negatively impact the receiving party, who regularly experiences differential treatment based on sex, race, ethnicity, or other social identities. The effects of microaggressions extend beyond personal offense to include anxiety, depression, and even hypertension. ${ }^{1,2}$

Addressing microaggressions can be challenging. Given that the recipients of microaggressions are often burdened with responding to them, it is important for bystanders to be empowered to respond as well. A bystander witnesses and recognizes the microaggression and can address it. Based on the work of Sue et al, ${ }^{3}$ we suggest that bystanders adopt the following strategies:

- Make the "invisible" visible. Many people do not perceive their actions as biased or prejudiced. It is therefore important to bring the implicit bias to the forefront by asking for clarification, naming the implication, or challenging the stereotype.

- Disarm the microaggression. Don't be afraid to stop, deflect, disagree, or challenge what was said or done, thereby highlighting its potentially harmful impact. Another option is

*Corresponding author: Melanie F Molina, MD; Email: mfmolina@partners.org; Telephone: 617-732-5636; Twitter: @MelMolinaMD.

Received: August 4, 2020; Accepted: August 6, 2020

๑) 2020 Society of Hospital Medicine DOI 10.12788/jhm.3519 to interrupt the comment as it's being said and redirect the conversation.

- Educate the speaker. Create a nonpunitive discussion by appealing to common values, promoting empathy, and increasing awareness of societal benefits. The speaker may become defensive and emphasize that their intent was not to cause harm. You must emphasize that, regardless of intent, the impact was hurtful. You may refocus the discussion with a simple statement such as, "I know you meant well, and..."

- Seek external support when needed. Addressing microaggressions can be emotionally taxing. Don't be afraid to utilize community services, find a support group, or seek advice from professionals.

By virtue of being a neutral third party, bystanders who intervene may have greater success at explaining the impact of the microaggression. In doing so, the bystander also relieves the recipient of the microaggression of a burdensome response. In the above example, another provider in the PACU might pull the nurse aside later and say, "When you asked the junior resident if he was leading the code, you unintentionally indicated that he was the most experienced, which made it more challenging for the female senior resident to lead the response." In this way, the "invisible" implication of the nurse's words-that the male resident was the most knowledgeable physician in the room -is made visible, and the female resident is relieved of responding.

Microaggressions do not occur in a vacuum; context matters. Before employing these strategies, consider when, where, and how you address microaggressions. These strategies validate and support those on the receiving end of microaggressions, and thus counteract their deleterious effects. The onus is on us: we must not be silent.

Disclosures: The authors have nothing to disclose.

\section{References}

1. Sue DW, Capodilupo CM, Torino GC, et al. Racial microaggressions in everyday life: implications for clinical practice. Am Psychol. 2007;62(4):271-286. https://doi.org/10.1037/0003-066x.62.4.271

2. Torres MB, Salles $A$, Cochran A. Recognizing and reacting to microaggressions in medicine and surgery. JAMA Surg. 2019;154(9):868-872. https://doi. org/10.1001/jamasurg.2019.1648

3. Sue DW, Alsaidi S, Awad MN, Glaeser E, Calle CZ, Mendez N. Disarming racial microaggressions: microintervention strategies for targets, White allies, and bystanders. Am Psychol. 2019;74(1):128-142. https://doi.org/10.1037/ amp0000296 